\title{
METROLOGICAL RESEARCHES OF NATIONAL PRIMARY STANDARD MACHINE FOR LEEB HARDNESS SCALES
}

\author{
A. Aslanyan ${ }^{1,2}$, E. Aslanyan ${ }^{1}$, S. Gavrilkin ${ }^{1}$, A. Shchipunov ${ }^{1}$ \\ ${ }^{1}$ VNIIFTRI, Mendeleevo, Moscow region, Russian Federation, \\ 2 Andrey_aslanyan@vniiftri.ru
}

\begin{abstract}
:
The paper describes the study of metrological characteristics of the National primary standard machine for Leeb hardness scales. The data on the contribution of various values to the extended uncertainty of hardness measurements are presented.

Keywords: Leeb hardness; National primary standard machine; Expanded uncertainty

\section{INTRODUCTION}

From 2016 to 2018, VNIIFTRI improved the National primary standard machine for Shore D hardness scales for metals [1]. It was improved by introducing into the standard machine devices that measure the hardness of metals on the Leeb D and $\mathrm{G}$ scales. The modernization of the standard was necessary to ensure the traceability of hardness testers that implement the Leeb method to the National primary standard of hardness. The paper presents the values of the main components of the expanded uncertainty of measurements on the National primary standard machine for Leeb hardness scales.
\end{abstract}

\section{DESCRIPTION OF THE WORK}

The process of reproducing the hardness numbers on the Leeb scales consists in the fall of a impact body with a diamond, ceramic or tungsten tip on a sample or hardness test block and in determining the ratio between the rebound and impact velocity of the impact body [2]. The hardness numbers on the Leeb scales are determined by the formula

$$
H L=\frac{1000 v_{r}}{v_{i}}
$$

where $v_{r}$ is a rebound velocity of impact body; $v_{i}$ is a impact velocity of impact body. The mass of impact body, radii of the tip of impact body, impact velocity, material of the tip are standardized for each Leeb scale. The most common Leeb scales in industry are Leeb $D$ and Leeb $G$ scales. Requirements for these scales are presented in Table
1 , where $r$ is a radius of the tip of impact body, $m$ is a mass of impact body.

Table 1: Requirements for Leeb scales D and G

\begin{tabular}{|l|l|l|}
\hline Requirements & HLD & HLG \\
\hline$m, \mathrm{~g}$ & $5.45 \pm 0.03$ & $20.00 \pm 0.03$ \\
\hline$r, \mathrm{~mm}$ & $1.500 \pm 0.003$ & $2.500 \pm 0.003$ \\
\hline$v_{i}, \mathrm{~m} / \mathrm{s}$ & $2.0500 \pm 0.0025$ & $3.000 \pm 0.005$ \\
\hline
\end{tabular}

Devices for Leeb hardness measuring consists of tubes with electromagnetic coils, impact bodies with built-in magnets, a mechanical device for resetting impact bodies. After faulting the impack body and its passage through the coil, an electromotive force (EMF) is induced in it, which is fixed by an electronic unit. The ratio of maximum voltage after impact and before it is equal to the ratio of the impact velocity to the rebound velocity of the impact body. The electronic unit recalculates this ratio into hardness numbers on Leeb scale.

The expanded uncertainty of measurement of hardness values on the Leeb scales affected by deviations from the nominal values of mass and radius of the tip of impact body, the impact velocity of impact body, the uncertainty of the measurement of the ratio of velocity at the time of rebound of the impact body at the moment of impact.

When improving the primary standard machine, the traceability of all values that affect the reproduction of hardness numbers to the national primary machines is ensured: units of mass kilogram, units of length-meter, units of time second, units of voltage - volt.

The masses of the impact bodies were measured using weights, and the radii of the tips of the impact bodies were measured using a profilometer. The impact velocity was measured using a laser triangulation displacement sensor.

The displacement sensor was attached to the reference tube in a special holder. The impact body fell down the tube, the sensor, depending on the displacement of the impact body, issued an electrical signal with a frequency of $400 \mathrm{kHz}$. The time intervals during which the impact body passed the measured displacement were measured by an 
oscilloscope. The oscilloscope also measured the electrical voltage on the sensor, which was converted into displacement using the calibration function. The resulting dependence of the displacement of the impact body on time determines the velocity of the fall of the impact body. In parallel, the oscilloscope measured the voltage on the electromagnetic coil through which the impact body flew. The moment of impact of the impact body on the hardness test block was determined using an oscilloscope at the point of transition of the "Voltage - time" curve in a straight line when the impact body flew through a tube with a coil. The standard uncertainty of measurement of displacement by the sensor was determined from the "Voltage-displacement" calibration curve.

The velocity of an impact body with a magnet passaging through an electromagnetic coil is proportional to the voltage induced on the coil. The ratio of the impact body velocity when it is impact to the impact body velocity when it is rebound is equal to the ratio of voltages at these times. The electrical voltages generated on the coil after passage through it the sides with the magnet were measured using an oscilloscope connected to the coil in parallel with the electronic unit.

The sensitivity coefficients of the influencing quantities included in equation (1) were determined by differentiating equation (1) by the influencing quantity. The sensitivity coefficients of values not included in equation (1) were found experimentally.

Among the values not included in equation (1) are the radius of rounding of the impact body and the mass of the impact body. The sensitivity coefficients for these values were determined by a small change in only one parameter and determining the change in hardness. The sensitivity coefficient is equal to the ratio of the change in hardness to the change in this parameter.

Table 2: The sensitivity coefficients of influence quantities

\begin{tabular}{|c|c|c|}
\hline Influencing values & $\begin{array}{l}\text { Hardness } \\
\text { level, HLD }\end{array}$ & $\begin{array}{l}\text { Sensitive } \\
\text { coefficients }\end{array}$ \\
\hline \multirow[t]{3}{*}{ Mass of impact body } & 466 & $-21.3 \mathrm{HLD} / \mathrm{g}$ \\
\hline & 601 & $-18.7 \mathrm{HLD} / \mathrm{g}$ \\
\hline & 765 & $-9.4 \mathrm{HLD} / \mathrm{g}$ \\
\hline \multirow{3}{*}{$\begin{array}{l}\text { Radii of the tip of } \\
\text { impact body }\end{array}$} & 466 & 314.1 HLD/mm \\
\hline & 601 & $286.3 \mathrm{HLD} / \mathrm{mm}$ \\
\hline & 765 & 201.5 HLD/mm \\
\hline \multirow[t]{3}{*}{ Impact velocity } & 466 & $-227.3 \mathrm{HLD} \cdot \mathrm{s} / \mathrm{m}$ \\
\hline & 601 & $-293.2 \mathrm{HLD} \cdot \mathrm{s} / \mathrm{m}$ \\
\hline & 765 & $-372.7 \mathrm{HLD} \cdot \mathrm{s} / \mathrm{m}$ \\
\hline $\begin{array}{l}\text { The ratio of the impact } \\
\text { body velocity to the } \\
\text { impact body velocity }\end{array}$ & All range & 1000 HLD \\
\hline
\end{tabular}

Table 2 shows the sensitivity coefficients for values that affect the Leeb $D$ hardness measurements.

Table 3 shows the sensitivity coefficients for values that affect the Leeb $G$ hardness measurements.

Table 3: The sensitivity coefficients of influence quantities

\begin{tabular}{|l|c|l|}
\hline Influencing values & $\begin{array}{l}\text { Hardness } \\
\text { level, HLG }\end{array}$ & $\begin{array}{l}\text { Sensitive } \\
\text { coefficients }\end{array}$ \\
\hline \multirow{3}{*}{ Mass of impact body } & 426 & $-19.5 \mathrm{HLG} / \mathrm{g}$ \\
\cline { 2 - 3 } & 560 & $-14.3 \mathrm{HLG} / \mathrm{g}$ \\
\cline { 2 - 3 } & 636 & $-7.9 \mathrm{HLG} / \mathrm{g}$ \\
\hline Radii of the tip of impact \\
body & 426 & $293.1 \mathrm{HLG} / \mathrm{mm}$ \\
\cline { 2 - 3 } & 560 & $245.3 \mathrm{HLG} / \mathrm{mm}$ \\
\cline { 2 - 3 } & 636 & $189 \mathrm{HLG} / \mathrm{mm}$ \\
\hline Impact velocity & 426 & $-142 \mathrm{HLG} \cdot \mathrm{s} / \mathrm{m}$ \\
\cline { 2 - 3 } & 560 & $-186.7 \mathrm{HLG} \cdot \mathrm{s} / \mathrm{m}$ \\
\cline { 2 - 3 } & 636 & $-211.7 \mathrm{HLG} \cdot \mathrm{s} / \mathrm{m}$ \\
\hline $\begin{array}{l}\text { The ratio of the impact } \\
\text { body velocity to the } \\
\text { impact body velocity }\end{array}$ & All range & $1000 \mathrm{HLG}$ \\
\hline
\end{tabular}

Table 4 shows the standard measurement uncertainty values that affect the reproduction of hardness numbers on the scales HLD, HLG.

Table 4: The contribution of influencing values to the standard combined uncertainty of hardness measurements on the Leeb scales

\begin{tabular}{|l|c|c|}
\hline Influencing values & HLD & HLG \\
\hline Mass of impact body & 0.06 & 0.09 \\
\hline Radii of the tip of impact body & 0.12 & 0.09 \\
\hline Impact velocity & 0.75 & 0.64 \\
\hline $\begin{array}{l}\text { The ratio of the impact body } \\
\text { velocity to the impact body } \\
\text { velocity }\end{array}$ & 1.29 & 1.22 \\
\hline
\end{tabular}

The standard combined uncertainty of measurement on Leeb hardness scale HLD is no more than 1.5. The expanded uncertainty of measurements on the Leeb HLD scale with a coverage factor of 2 is no more than 3.0.

The standard combined uncertainty of measurement on Leeb hardness scale HLG is no more than 1.39, and the expanded uncertainty of measurements on the HLG scale with a coverage factor of 2 is no more than 2.8 .

\section{SUMMARY}

Metrological researches of the National primary standard machine allowed us to estimate the expanded uncertainty of measurements on the Leeb HLD and HLG hardness scales. 


\section{REFERENCES}

[1] E. G. Aslanyan, M. V. Balakhanov, N. S. Gusyatinskaya, A. S. Doinikov, V. I. Kozlov, N. A. Safarov, V. R. Shlegel, Measurement Techniques, vol. 45, no. 3, pp. 223-227, 2002.
[2] K. Herrmann, Hardness Testing Principles and Applications. Leeb Method, Published by ASM International, Novelty, USA, pp. 78-86, 2011. 